\title{
Absence of impact of aerial malathion treatment on Aedes aegypti during a dengue outbreak in Kingston, Jamaica
}

\author{
Trevor Castle, ${ }^{1}$ Manuel Amador, ${ }^{2}$ Samuel Rawlins, ${ }^{3}$ \\ J. Peter Figueroa, ${ }^{1}$ and Paul Reiter ${ }^{2}$
}

ABSTRACT During an outbreak of dengue fever in Jamaica from October to December 1995, a study was carried out to determine the impact of aerial ultra-low volume malathion treatment on adult Aedes aegypti. This was done by monitoring oviposition rates of the vector in three urban communities in Kingston and by exposing caged mosquitoes both directly and indirectly to the aerial malathion treatment. The insecticide was delivered at a rate of $219 \mathrm{~mL} / \mathrm{ha}$ between 7:10 a.m. and 8:45 a.m. The results of the study clearly showed that the insecticide application was ineffective in interfering with Aedes aegypti oviposition, and adult mosquitoes held in cages inside dwellings were largely unaffected. Consequently, this type of intervention seemed to have little significant impact in arresting or abating dengue transmission.

Aedes aegypti is the only known vector of dengue, dengue hemorrhagic fever (DHF), and dengue shock syndrome in the Caribbean, and the virus and its vector have challenged the well-being of the Caribbean people, as well as the vital tourist trade on which

1 Jamaica, Ministry of Health, Kingston, Jamaica. Address correspondence to Trevor Castle (or to Samuel Rawlins, address given below at ${ }^{3}$ ) at: Epidemiology Unit, Ministry of Health, Oceana Building, 2 King Street, Kingston 5, Jamaica.

2 United States Public Health Service, Centers for Disease Control, San Juan Laboratories, San Juan, Puerto Rico.

3 Pan American Health Organization/World Health Organization, Caribbean Epidemiology Centre, Port of Spain, Trinidad. Address correspondence to this author at: CAREC, P.O. Box 164, Port of Spain, Trinidad, Republic of Trinidad and Tobago. Telephone: (868) 622-2324; fax: (868) 628-9084.

Email: Rawlinsa@carec.paho.org nearly all the countries of the area rely (1-6).

Public health authorities in the Caribbean have advocated managing this mosquito at its source by eliminating containers that harbor Ae. aegypti. In the case of nondisposable containers (7), insecticide use has been recommended and instituted in most of the 21 countries that belong to the Caribbean Epidemiology Center (CAREC), an institution affiliated with the Pan American Health Organization and that provides laboratory reference and epidemiology services to the CAREC Member Governments.

While the primary approach to Ae. aegypti management in the Caribbean continues to be source reduction, if Ae. aegypti-transmitted disease occurs, environmental management has obvi- ously been inadequate and swift measures are required to limit transmission. In order to control a dengue epidemic, Giglioli (8) postulated the need for an immediate minimum $97 \%$ reduction of adult Ae. Aegypti. One way to do that may be with such rapid adulticidal measures as ultra-low volume (ULV) sprays (9). In an emergency, aerial and ground ULV applications of insecticides could quickly disperse the toxicants over a wide geographic area.

Gubler (10), however, expressed little faith in the effectiveness of ULV applications on wild Ae. aegypti populations. Conversely, Gratz (9) argued that ULV applications of insecticide during disease outbreaks appeared to be the only measure available for emergency control of Aedes vectors in 
most urban and periurban areas. There are several instances of aerial ULV application of malathion for $A e$. aegytpi control which were deemed successful, as in the case of Uribe et al. (11) in Buga, Colombia, and Perich et al. (12) in the Dominican Republic. On the other hand, there are instances where aerial applications had to be repeated to obtain the desired effect (13, 14). Dosage, droplet size, conditions of applications, the physical environment, and basic susceptibility of the host mosquito could all affect the impact of the ULV treatment.

The only previous experience with aerial ULV malathion treatment for Ae. aegypti control in the Englishspeaking Caribbean was in the 1977 dengue/DHF epidemic in Jamaica. Moody et al. (15) reported a 70-100\% bioassay success on caged Ae. aegypti when $96 \%$ technical grade of malathion was applied in the main urban areas of the country, using single-engine aircraft and truck-mounted equipment. Because of this measure of apparent success in the 1977 epidemic and despite the expressed reservations of the local scientists, the Ministry of Health of Jamaica considered it worthwhile to intervene in a 1995 epidemic with aerial ULV malathion treatments.

On 6 October 1995 the Ministry of Health officially informed the Jamaican public of a dengue fever outbreak in the country. The Ministry then launched a major dengue control program, emphasizing public education, community mobilization, and clean-up campaigns. Over the course of the epidemic in 1995, a total of 1884 suspected cases were reported, including 108 cases of dengue hemorrhagic fever, 3 cases of dengue shock syndrome, and 4 deaths.

On 8 November 1995, aerial ULV malathion spraying was done in the metropolitan Kingston and St. Andrew area, which consists of the capital city of Kingston and the urban portion of the adjacent parish of St. Andrew. In an assessment carried out by this study's authors of the spraying's effect on caged Ae. aegypti mosquitoes at three outdoor sites, there was $100 \%$ mortality at two of the sites, and $50 \%$ died at the third site. At nine indoor or partly indoor sites all the mosquitoes survived the treatment. Thus the effectiveness of the aerial spraying was considered relatively low and brought into question the value and cost of the operation.

Despite its likely limited impact, a second treatment was scheduled for 19 November 1995. Since a scientific evaluation of the effectiveness of aerial ULV malathion intervention could be extremely useful for future requests by Caribbean and other vector control authorities for appropriate tools for rapid response to a dengue epidemic, the present study was designed and executed.

The impact of aerial ULV malathion on the Ae. aegypti populations was assessed by monitoring oviposition rates in three sections of Kingston: Hughenden, Richmond Park, and Vineyard Town. At the same time, adult mosquito bioassays were used to assess the penetrative action of the aerially dispensed malathion, as well as the extent of the insecticidal coverage.

The Kingston/St. Andrew urban area is densely populated and has over 800000 residents, with concrete and wooden homes that are generally close to each other. There is also a large amount of vegetation between homes, which could affect the penetration of ULV droplets into residences and thus the insecticide's impact on the endophilic Ae. aegypti mosquitoes.

To study oviposition rates, paired enhanced oviposition traps (16) containing 4-day-old hay infusion were used for daily (24-hour) egg collection at 30 preselected residences in each of the three study areas. Egg collections were made on seven consecutive days: the two days before the aerial spraying, the day of the spraying (19 November 1995), and the next four days. The mean egg production per site-day was calculated. Daily servicing of the ovitraps was done between 9:00 a.m. and 11:00 a.m.

Adult mosquito bioassays were done with cages holding 3-day-old female Ae. aegypti that were exposed either directly or indirectly to the insecticidal treatment at seven widely distributed sites that were selected randomly and were considered as representative of the entire Kingston/St. Andrew area. The bioassay cages were retrieved and returned to the laboratory 1 hour after the completion of the spraying operations.

On 19 November 1995 the Kingston/ St. Andrew metropolitan area was treated with $95 \%$ malathion applied by two Thrush Commander S2R aircraft, flown at a height of 30 to 45 meters and a speed of $192 \mathrm{~km} / \mathrm{h}$. The insecticide was delivered at a rate of $219 \mathrm{~mL} / \mathrm{ha}$ (3 fluid ounces per acre), with aerosol droplet size estimated at 10-15 microns. Spraying was done between 7:10 a.m. and 8:45 a.m. The meteorological conditions seemed conducive to aerial spraying, with a mean wind speed of 5.6 to $9.3 \mathrm{~km} / \mathrm{h}$ and a mean temperature of $26.4^{\circ} \mathrm{C}$.

The data from the bioassay of caged mosquitoes (Table 1) showed that

TABLE 1. Mortality (percent) of caged adult female Aedes aegypti mosquitoes following aerial ULV spraying with malathion, Kingston, Jamaica, November 1995

\begin{tabular}{lcc}
\hline \multicolumn{1}{c}{ Sentinel station } & Indoor cage & Outdoor cage \\
\hline 1. Harbour View & 0 & 0 \\
2. Pembroke Hall & 0 & 88 \\
3. Cherry Gardens & 0 & 12 \\
4. Hope Pastures & 7 & 29 \\
5. Eastwood Park & 71 & 56 \\
6. Passmore Town & 0 & 100 \\
7. National Public Health Lab. & - & 100 \\
$\quad$ Control & 0 & - \\
\hline
\end{tabular}


mortality in seven outdoor cages was variable and reasonably good, ranging from $12 \%$ to $100 \%$, except in the Harbour View area, where the mosquitoes were unaffected by the aerial ULV spraying. There was a mean 55\% kill. Conversely, the mean mortality rate in six indoor mosquito cages was a mere $13 \%$, ranging from $0 \%$ to $7 \%$ in five of the sites and reaching a high of $71 \%$ in just the bioassay cage at Eastwood Park.

The high prevalence of gravid Ae. aegypti in all three study areas was a remarkable determinant feature of the dengue epidemic in the Kingston area. For example, on 19 November, the day of aerial ULV spraying, $62 \%$ to $72 \%$ of the homes with ovitraps were positive for Ae. aegypti eggs. In two of the three study areas the proportion of homes with positive ovitraps continued to rise after the intervention. The rate subsequently went as high as $93 \%$ (Figure 1). In a similar manner, there was no dramatic overall reduction in the number of eggs of Ae. aegypti per house per day deposited after the ULV sprays (Figure 2).

The epidemic peaked in the Kingston/St. Andrew metropolitan area around the week of 18 November, that is, two weeks after it peaked in the rural parishes. In both areas, the peak was followed by a marked decline (Figure 3). After the first aerial treatment, on 8 November, the epidemic continued its upward trend in Kingston and St. Andrew for the next 10 days. There was then an abrupt decrease in reported cases beginning on or about the date of the second aerial application, 19 November. The decline continued for the next two weeks, followed by a sharp, brief rise and then a gradual fall.

The decision to undertake aerial ULV malathion spraying was based on an assumption the treatment would rapidly reduce the adult $A$ e. aegypti population by at least $97 \%$, as postulated by Giglioli (8), with a concomitant fall in dengue virus transmission. The expectation, therefore, was that there would be a significant decline both in the percentage of houses with gravid mosquitoes and in mosquito egg pro-
FIGURE 1. Percentages of houses with positive ovitraps, Kingston, Jamaica, November 1995

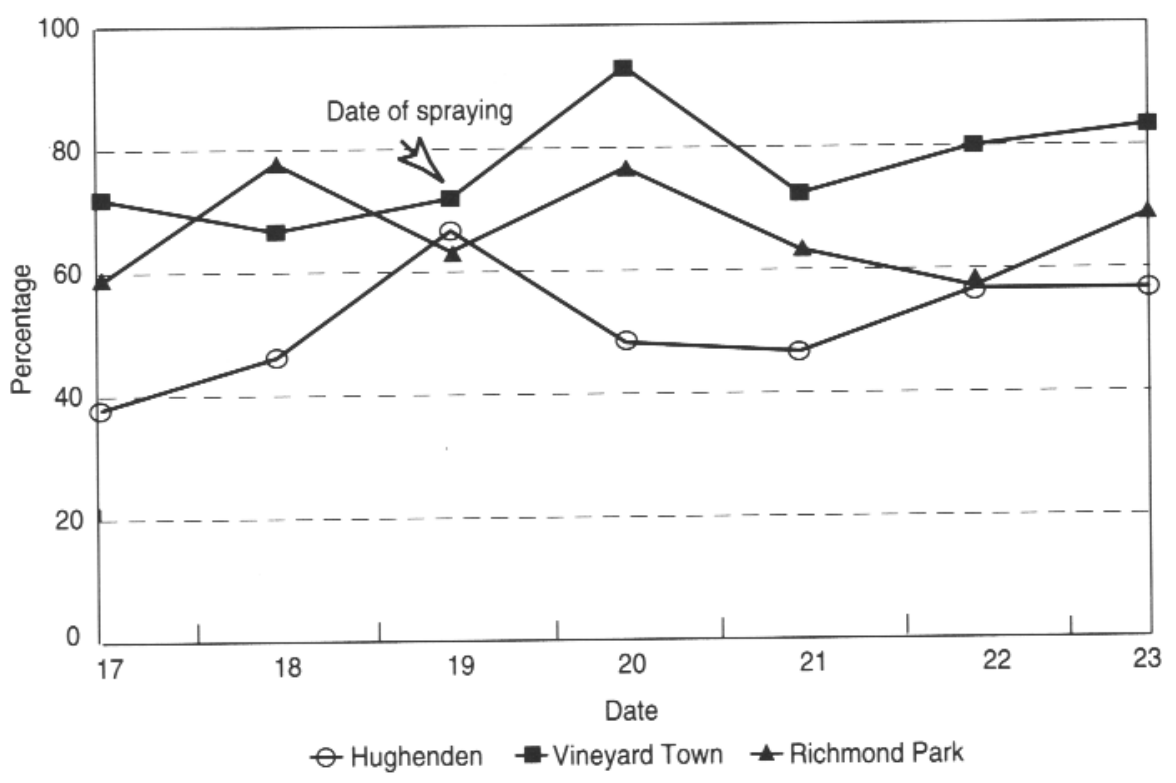

FIGURE 2. Mean number of eggs per house per day, Kingston, Jamaica, November 1995

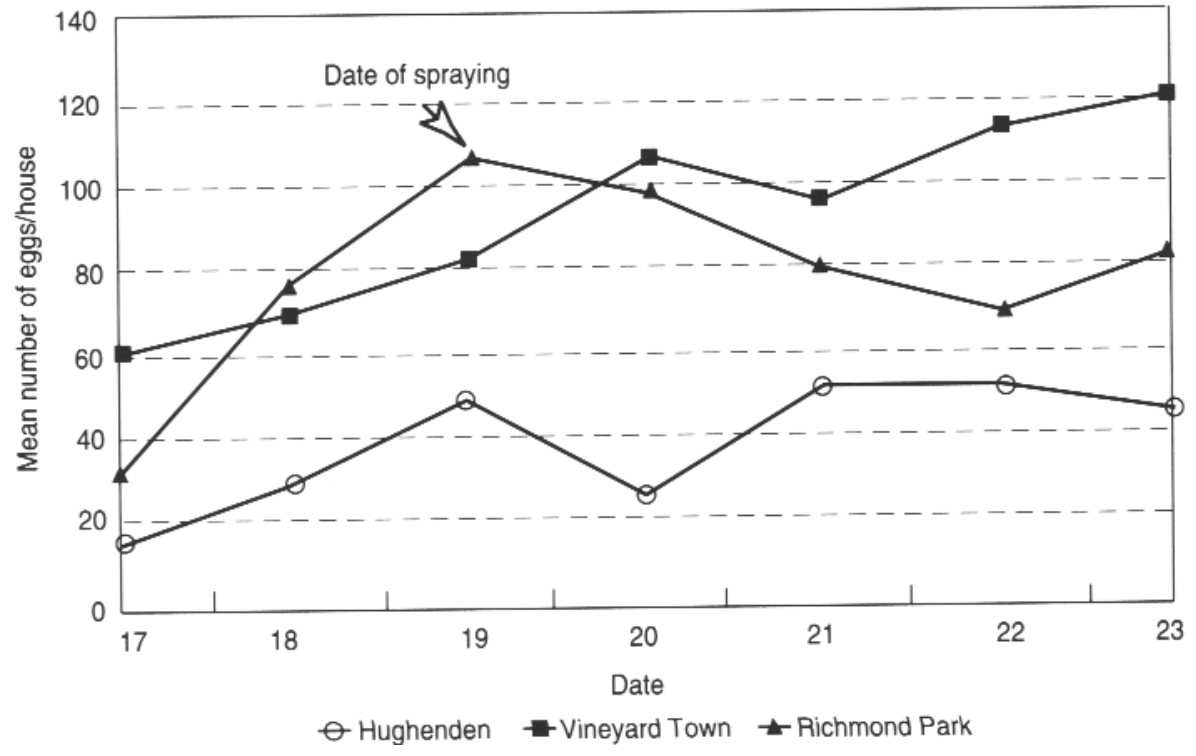

duction following treatment. However, the results of this study clearly demonstrated that the insecticidal intervention proved ineffective in interfering with Ae. aegypti oviposition activity.

The mortality of caged mosquitoes was unimpressive in both the outdoor locations (mean kill of 55\%) and the indoor ones (mean kill of $13 \%$ ). Therefore, it was not surprising that there was no impact after the intervention on either the oviposition rate or the proportion of homes found positive for gravid Ae. aegypti. In the aerial 
FIGURE 3. Reported cases of dengue, Kingston/St. Andrew vs. other parishes in Jamaica, August 1995-January 1996

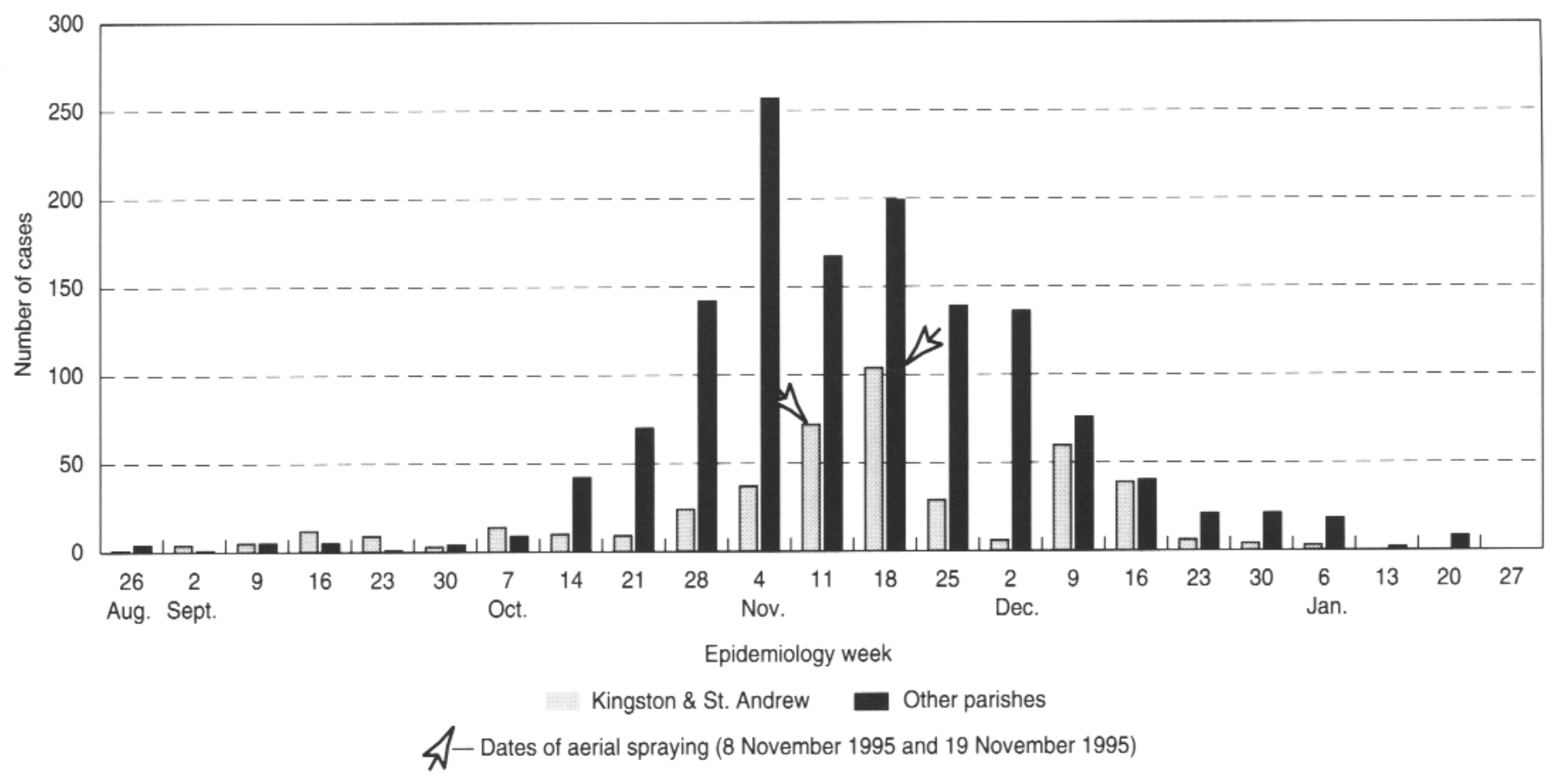

spray treatment of Kingston in 1977, Moody et al. (15) reported $70-100 \%$ mortality, which was thought to have affected the outcome of the epidemic. However, because of simultaneous ground and aerial ULV treatments, it was not possible to specifically determine the impact of aerial ULV treatment on the Ae. aegypti population.

Closer examination of the results of other aerial ULV interventions, such as Perich et al. (12), indicated that after single spray treatments, fairly good mortality of Ae. aegypti was obtained outdoors, but little or no impact was detected at various indoor locations. Repeated aerial sprays were effective in Buga, Colombia, (11) and the southeastern United States of America (13). In the latter case, it took a twice-weekly treatment regime of $35.5 \mathrm{~mL} / \mathrm{ha}$ of malathion over an 11-week treatment period (22 treatments total) to completely interrupt Ae. aegypti oviposition, a goal not achieved with the two Kingston/St. Andrew aerial applications 11 days apart. Thus, repeated or sequential aerial treatment may prove successful over a period of time. But such success still would not meet our current requirement of rapid interruption of the Ae. aegypti population in order to break the ongoing dengue epidemic.

Another issue that may have affected the outcome of the present intervention is dosage. The second Kingston/St. Andrew spraying used only $219 \mathrm{~mL} / \mathrm{ha}$, though as much as $682 \mathrm{~mL} / \mathrm{ha}$ was found to be effective in Buga, Colombia (11). This high dosage contrasted with the $50 \mathrm{~mL} / \mathrm{ha}$ permitted in the United States (9). In Jamaica, there were no legal limits on the dosage, but the public's tolerance of the malathion was an important consideration. The unpleasant smell of higher dosages of malathion may have contributed to the residents' failure to open their doors and windows early in the morning, thus limiting the penetration of the chemical and the impact on the endophilic mosquitoes. In addition, the impressive vegetational cover which characterizes much of Kingston and St. Andrew could have caused the entrapment of a fair quantity of the insecticide droplets in their descent to the targeted sites. These possibilities are supported by the results obtained from bioassays of adult mosquitoes in indoor cages.

We do not believe that reduced sensitivity to insecticides was an important factor in the failure of these control efforts. In comparison to a mosquito strain kept at the CAREC facilities in Trinidad for 16 years without exposure to any chemicals, the Hughenden and Richmond Park strains of Jamaica larval Ae. aegypti only showed 3.5 and 2.5 resistance ratios respectively to temephos $(17,18)$. The Jamaican strains were among the Caribbean populations most sensitive to the organophosphate insecticide. Against malathion, adult Richmond Park and Hughenden strains only showed 2.2 and 3.6 resistance ratios respectively in comparison to the same susceptible CAREC strain (18).

The dengue surveillance data (Figure 3) could imply an effect of aerial treatment on transmission. However, this conclusion is definitely not supported by the entomological evaluation and may therefore be artifactual. 
The fall in reported cases in the Kingston/St. Andrew metropolitan area coincided with a waning epidemic in the rural parishes, which had not been subjected to air sprays. This suggests the effect of a factor unrelated to aerial spraying: the increasing dengue-immune status of the human population.

As the expression says, "Dead mosquitoes don't lay eggs!" Nevertheless, this study has demonstrated that aerial ULV malathion spraying exerted no adverse effect on the oviposition rate of the adult population and consequently seemed unlikely to significantly arrest or abate dengue transmission. Given the calculated cost of

1. Caribbean Epidemiology Centre. Annual report. Port of Spain, Trinidad: CAREC; 1995.

2. Caribbean Epidemiology Centre. Annual report. Port of Spain, Trinidad: CAREC; 1996.

3. Caribbean Epidemiology Centre. Fax alert: Dengue virus type 3 in Puerto Rico. Port of Spain, Trinidad: CAREC; 1998.

4. Nathan MB, Knudsen AB. Aedes aegypti infestation characteristics in several Caribbean countries and implications for integrated community-based control. J Am Mosq Control Assoc 1991;7:400-404.

5. Pan American Health Organization. Dengue and dengue hemorrhagic fever in the Americas: guidelines for prevention and control. Washington, DC: PAHO; 1994. (Scientific publication 548).

6. Nathan MB. Critical review of Aedes aegypti control programs in the Caribbean and selected neighboring countries. J Am Mosq Control Assoc 1993;9:1-7.

7. Rosenbaum J, Nathan MB, Ragoonansingh R, Rawlins SC, Gayle C, Chadee DD, et al. Community participation in dengue prevention and control: a survey of knowledge, attitudes, and practice in Trinidad and Tobago. Am J Trop Med Hyg 1995; 53:111-117.

8. Giglioli MEC. Aedes aegypti programs in the Caribbean and emergency measures against the dengue pandemic of 1977-
US\$ 30000 for a morning's spray operations, it seemed unlikely that the apparent requirement of a number of sequential treatments would be attractive or possible in Jamaica or most other Caribbean countries.

The study suggests that a single aerial spray is not an effective rapid response as a control measure for dengue fever outbreaks. Sustained routine efforts by the vector control authorities and the community during interepidemic periods, such as in source reduction and environmental sanitation, are probably much more effective. They are also more economical, especially for poor countries, in preventing high prevalences of gravid
Ae. aegypti and an accompanying dengue epidemic.

Acknowledgements. We acknowledge with gratitude the contributions made to this study by the following organizations and individuals: the Pan American Health Organization, for providing financial assistance and support; the Jamaican Defence Force, the Ministry of Health, and the Kingston and St. Andrew Health Department, for providing personnel to assist with the field operations; and Ms. Karen Polson and Ms. Norma McKenzie of the Ministry of Health Vector Control Unit.

\section{REFERENCES}

1978; a critical review. In: Dengue in the Caribbean. Washington, D.C.: Pan American Health Organization; 1979; 133-152. (Scientific Publication No. 375).

9. Gratz NG. Emergency control of Aedes aegypti as a disease vector in urban areas. J Am Mosq Control Assoc 1991;7(3): 353-365.

10. Gubler DJ. Aedes aegypti and Aedes aegyptiborne disease control in the 1990's: top down or bottom up? Am J Trop Med Hyg 1989;40:571-578.

11. Uribe LJ, Garrido MG, Nelson M, Tinker ME, Moquillaza J. Experimental aerial spraying with ultra-low volume (ULV) malathion to control Aedes aegypti in Buga, Colombia. Bull Pan Am Health Organ 1984;18:43-57.

12. Perich MJ, Tidwell MA, Williams DC, Sardelis MR, Pena CJ, Mandeville D, et al. Comparison of ground and aerial ultralow volume applications of malathion against Aedes aegypti in Santo Domingo, Dominican Republic. J Am Mosq Control Assoc 1990;6(1):1-6.

13. Eliason DA, Kilpatrick JW, Babbitt MF. Evaluation of the effectiveness of the ultra low volume aerial application of insecticides against Aedes aegypti in Florida. Mosq News 1970;30:430-436.

14. United States of America, Department of Health and Human Services, Centers for Disease Control. Efficacy of aerial applica- tion of Dibrom 14 against Aedes aegypti in San Juan, Puerto Rico. San Juan, Puerto Rico: CDC; 1987. (Dengue Surveillance Summary 47).

15. Moody C, Bowen-Wright C, Murray J, Castle T, Barrett M, Dunkley G, Watson L, et al. Emergency control of vectors during a dengue outbreak in Jamaica, 1977. In: Dengue in the Caribbean. Washington, D.C.: Pan American Health Organization; 1979:87-97. (Scientific Publication No. 375).

16. Reiter P, Amador MA, Colon N. Enhancement of the CDC ovitrap with hay infusions for daily monitoring of Aedes aegypti populations. J Am Mosq Control Assoc 1991;7(1):52-55.

17. Rawlins SC, Hing Wan J. Resistance in some Caribbean populations of Aedes aegypti to several insecticides. J Am Mosq Control Assoc 1995;11:59-65.

18. Rawlins SC. Spatial distribution of insecticide resistance in Caribbean populations of Aedes aegypti and its significance. Rev Panam Salud Publica 1998;4(4):243-251.

Manuscript received on 25 April 1997. Revised version accepted for publication on 4 January 1999 
RESUMEN Durante un brote de dengue que ocurrió en Jamaica de octubre a diciembre de 1995, se llevó a cabo un estudio a fin de determinar el impacto del rociamiento con volúmenes muy bajos de malatión en mosquitos Aedes aegypti adultos. Se observaron las tasas de ovipostura del vector en tres comunidades urbanas de Kingston y se expusieron mosquitos colocados en trampas directa e indirectamente a rociamientos aéreos con malatión. El insecticida se roció a una velocidad de $219 \mathrm{~mL} / \mathrm{ha}$ entre las 7.10 y las $8.45 \mathrm{~h}$. Los resultados del estudio claramente demostraron que la aplicación del insecticida no interfirió con la ovipostura de Aedes aegypti, y los mosquitos adultos colocados en trampas dentro de las viviendas casi no sufrieron ningún efecto. Por consiguiente, este tipo de intervención parece haber tenido muy poco impacto en la interrupción o atenuación de la transmisión del dengue.

Falta de impacto del bajos en Aedes aegypti
durante un brote de dengue
en Kingston, Jamaica 